\title{
Shear stress regulation of nitric oxide production in uterine and placental artery endothelial cells: experimental studies and hemodynamic models of shear stresses on endothelial cells
}

\author{
BENJAMIN SPRAGUEE ${ }^{1,2}$, NAOMI C. CHESLER ${ }^{1}$ and RONALD R. MAGNESS*,2,3,4 \\ ${ }^{1}$ Dept. of Biomedical Engineering, University of Wisconsin-Madison, ${ }^{2}$ Dept. of Obstetrics and Gynecology, \\ Perinatal Research Laboratories, ${ }^{3}$ Dept. of Pediatrics and ${ }^{4}$ Dept of Animal Sciences, Madison USA
}

\begin{abstract}
Hemodynamic shear stress is the most powerful physiological regulator of endothelial Nitric Oxide Synthase (eNOS), leading to rapid rises in nitric oxide (NO). The substantial increases in uterine and placental blood flows throughout gestation rely heavily on the action of NO. We and others have investigated endothelial function in response to shear stress with cell culture models of shear stress. In order to apply the results of these studies more effectively, we need a more complete understanding of the origin and coupling of the hemodynamic forces and vascular tissue behavior. For example, equations commonly used to calculate in vivo shear stress incorporate assumptions of steady (non-pulsatile) blood flow and constant viscosity of blood (Newtonian fluid). Using computational models, we can estimate a waveform of shear stress over a cardiac cycle and the change in blood viscosity with shear rate and hematocrit levels, two variables that often change with size of vessel and location within a vascular tree. This review discusses hemodynamics as they apply to blood flow in vessels, in the hope that an integration of these fields can lead to improved in vitro shear stress experiments and understanding of NO production in uterine and placental vascular physiology during gestation.
\end{abstract}

KEY WORDS: pregnancy, shear stress, nitric oxide, blood flow, rheology

\section{Introduction}

Substantial increases in uterine and placental blood flow are the major hallmark of the cardiovascular adaptations seen during gestation (Magness, 1998; Magness and Zheng, 1996; Reynolds and Redmer, 1995). These alterations in perfusion develop in order to meet the dramatically increasing nutrient and metabolic needs of the growing fetus. The magnitude of this response makes it by far the most striking physiologic cardiovascular adaptation observed during pregnancy (Magness, 1998; Magness and Zheng, 1996; Reynolds and Redmer, 1995). In order to allow parallel pathways for blood to flow, vasodilation, along with substantial remodeling and angiogenic growth of these vascular beds, are responsible for the dramatic decrease in vascular resistance that permits the increase in blood perfusion without a dramatic rise in blood pressure. In contrast, a mild fall or no change in blood pressure is observed when systemic vascular resistance falls dramatically in pregnancy.

Because there is no innervation of fetal placental vessels, vasodilation has been thought to occur primarily by the efforts of locally produced vasodilators (Fox and Khong, 1990; Kwon et al., 2004; Myatt, 1992; Zheng et al., 2000). The most important fetal placental vasodilator may be nitric oxide (NO) because it is not only constitutively produced, but also dramatically stimulated by increases in shear stress which occurs with increased blood flow (Kuchan and Frangos, 1994; Li etal., 2003; Li etal., 2004; Li etal., 2005; Lie et al., 1970; Vequaud and Freslon, 1996). The growth and recruitment of parallel pathways for elevating blood flow and

Abbreviations used in this paper: cGMP, cyclic guanosine monophosphate; eNOS, endothelial nitric oxide synthase; IUGR, intrauterine growth restriction; L-NAME, Nw-nitro-L-arginine methyl ester; L-NNMA, NGmonomethyl-L-arginine acetate; NO, nitric oxide.

\footnotetext{
*Address correspondence to: Ronald R. Magness. Dept. Ob/Gyn, University of Wisconsin, Perinatal Research Labs, Atrium B, Meriter Hospital, 202 S. Park St., Madison, WI 53715, USA. Fax: +1-608-257-1304.e-mail: rmagness@wisc.edu
} 
other changes in the maternal and developing fetal vasculature are also determined in part by shear stress since it substantially affects alterations in gene expression in endothelial cells (McCormick et al., 2001) associated with altered proliferation, migration, orientation, stress fiber development and inflammatory responses (Gimbrone et al., 2000; Harrison et al., 1996; Nadaud et al., 1996).

We and others are investigating the role of endothelial-derived $\mathrm{NO}$ in adapting vascular function to pregnancy using cell culture and in vitro experimental models, by evaluating the endothelial cell transduction and signaling responses to shear stress (Cockell and Poston, 1997; Kublickiene et al., 2000; Li et al., 2003; Li et al., 2004; Li et al., 2005; Rowe et al., 2003). What has become quite evident, however, is that a clearer understanding is needed of the pattern and magnitude of in vivo shear stress within the uterine and placental vasculature. Furthermore, a better understanding of uterine and placental hemodynamics is critical to improved design of in vitro experiments and ultimately interpreting the clinical significance of the observed in vitro data. To this end, we are also evaluating the vascular growth and remodeling of these dramatically altered vessels in pregnancy, and how these changes are affected by increased shear stress secondary to increased blood flow and other hemodynamic changes (e.g. impedance, vascular remodeling, etc.).

Preeclampsia is characterized by reduced uterine vascular growth and less vascular remodeling than that in normal pregnancy in conjunction with higher blood pressure and restricted fetal growth especially during the third trimester. Therefore, we hypothesize that this pathophysiological condition serves as a significant case of disruption of the normal positive feedback mechanism of greater blood flow causing greater shear stress, having a remodeling effect to normalize shear stress, and thereby allowing greater blood flow. Our hypothesis is supported by studies showing that the NO-mediated pathway of artery dilation has been found to be impaired with preeclampsia (Cockell and Poston, 1997; Kublickiene et al., 2000), but not necessarily solely as a result of decreased NO production (Rowe et al., 2003). Therefore, measuring and understanding shear stress within the preeclamptic uterine arterial bed might also hint where the artery response to shear stress is most lacking and therefore most disrupted from the normal healthy vessel remodeling.

Herein we review the importance of NO production in pregnancy, experimental systems used to study the role of NO in pregnancy, the hemodynamic forces that act on vascular cells in vivo during pregnancy and the important and novel utility of mathematical and computer models for predicting forces and flows in vivo during pregnancy. It is our hope that future studies will take advantage of these mathematical and computer models to study the uterine and placental vasculature, paving the way for more sophisticated and relevant studies on the impact of blood flow changes (and thus shear stress changes) on the uterine and fetal placental vasculatures during healthy and pathologic pregnancies, where fetal growth is not optimal.

\section{Nitric oxide production}

NO synthesis is catalyzed by nitric oxide synthase (NOS), which converts $\mathrm{L}$-arginine to L-citruline, with $\mathrm{NO}$ as a free radical by-product (Mayer and Hemmens, 1997; Sladek et al., 1997).
There are three isoforms of nitric oxide synthase (NOS) that produce NO. The predominant constitutive NOS isoform within the endothelium is eNOS and its activation leads to reduced vascular tone. Shear stress and eNOS signaling activity are regulated by $\mathrm{Ca}^{2+} /$ calmodulin-dependent (Busse and Mulsch, 1990) and $\mathrm{Ca}^{2+}$-independent mechanisms. De novo NO produced by the endothelium is thought to be highly labile (t1/2 3-5 $\mathrm{sec}$ ) and is secreted adluminally to adjacent vascular smooth muscle cells where it binds to the heme binding region and activates soluble guanylate cyclase, which in turn converts GTP to cGMP (Itoh et al., 1998; Magness et al., 1996; Magness, 1998; Sladek et al., 1997). Inhibition of NOS using Nw-Nitro-L-arginine methyl ester hydrochloride (L-NAME) or NG-Monomethyl-L-arginine acetate salt (L-NMMA) increases arterial pressure, vascular resistance, and systemic pressor indicators i.e. vasoconstrictive responses to infused angiotensin II, norepinephrine, and arginine vasopressin (Baylis and Engels, 1992; Molnar and Hertelendy, 1992; Rosenfeld et al., 1996; Van Buren et al., 1992). The increased pressor responsiveness is reversed only by pretreatment with L-Arginine, but not D-Arginine, phentolamine, saralasin, or captopril (Conrad and Whittemore, 1992).

\section{Importance of nitric oxide}

Several vasodilators such as NO, natriuretic peptides (ANP/ BNP and CNP), endothelium-derived hyperpolarizing factor $(\mathrm{EDHF})$ and prostacyclin $\left(\mathrm{PGI}_{2}\right)$ are redundant mechanisms that collectively contribute to the low resistance of the uterine and placental vasculatures in normal pregnancy. NO is considered by numerous investigators to play an important, if not an essential, role in pregnancy-related vascular adaptation (Magness et al., 1997; Sladek et al., 1997). This premise is supported to a great extent by evidence that NO is released in greater amounts by fetoplacental and uteroplacental endothelium (Magness et al., 1997; Magness and Zheng, 1996; Sladek et al., 1997) during pregnancy. The level of NO and its second messenger cyclic guanosine monophosphate (cGMP) are substantially elevated during pregnancy (Magness et al., 1996; Magness et al., 1997; Magness et al., 2001; Rosenfeld et al., 1996; Sladek et al., 1997), especially in the uteroplacental and fetoplacental units (Magness et al., 1996; Magness et al., 2001; Sheppard et al., 2001; Xiao et al., 1997; Yang et al., 1996; Yi et al., 2005). Moreover, chronic inhibition of NO production induces small for gestational age (SGA) weights and intrauterine fetal growth restriction (IUGR) (Baylis and Engels, 1992; Yallampalli and Garfield, 1993) associated with decreases in fetoplacental blood flow (Chang et al., 1992). Furthermore, NO production by ovine placenta and eNOS protein expression in fetoplacental artery endothelium elevate gradually throughout the third trimester from $70-90 \%$ of gestation (110-130 days; term $=147$ days), the time of the most dramatic growth rate of the ovine fetus (Sheppard et al., 2001; Zheng et al., 2000). Studies utilizing animal models have demonstrated that prolonged inhibition of NO production during pregnancy causes fetal growth restriction probably by decreasing fetal placenta and/ or uterine blood flow (Baylis and Engels, 1992; Sladek et al., 1997; Yallampalli and Garfield, 1993). These data collectively establish a cause-and-effect relationship between locally produced endothelial derived NO and rises in blood flow to both the placenta and uterus to optimize fetal growth. 
Stripping the endothelium or pretreatment with the NOS inhibitor L-NAME has been shown to substantially reduce or abolish the acute flow-induced dilation of isolated vessels. Moreover, NO inhibition of flow-mediated vasodilation can be reversed by the NOS substrate L-arginine, demonstrating substrate specificity of this inhibitor for the eNOS enzyme (Fukaya and Ohhashi, 1996; Vequaud and Freslon, 1996). Considering first the placental circulation, a major focal point of this review, elevations in fetoplacental blood flow/shear stress also increase NO production, eNOS expression, and phosphorylation of eNOS via posttranslational modifications in ovine fetoplacental arterial endothelial (OFPAE) cells. In our recent papers on this topic ( $\mathrm{Li}$ et al., 2003; Li et al., 2004; Li et al., 2005), we have focused primarily on eNOS because it is the only NOS family isoform identified in the endothelium of ovine fetoplacental vascular bed (Sheppard et al., 2001; Zheng et al., 2000). Additional projects contrasting the unique developmental responses of the uterine vascular bed in pregnancy are in progress.

\section{Experimental models to induce shear stress on endothelial cells in vitro}

In vivo studies with various controlled flow rates can well demonstrate the dilatory effects of shear stress using noninvasive imaging techniques. However, to draw more definitive conclusions about shear stress responses from these results that can go beyond the individual observations, shear stress must be accurately quantified. In vivo measurements of shear stress during each cardiac cycle in a pulsatile fashion however, are very technically difficult. Therefore measurements of average or mean physiological flow rates and diameters are typically obtained. From these values, shear stress values are calculated based on assumed Newtonian properties of the blood and ignoring blood flow pulsatility. Although calculating shear stress in this way introduces some error, which may obscure important findings, it must be recognized that this is indeed the first step needed to define what is physiologically and clinically relevant.

To address the need to study cells in well-controlled shear stress environments, in vitro systems have been created for endothelial cell culture and have been invaluable for showing the impact of shear stress on endothelial cell signaling events, such as those related to NO. The most prevalent systems for exposing cells to defined shear stress are parallel plate and cone-and-plate apparati (Davies etal., 1986; Levesque and Nerem, 1985). In both systems, endothelial cells that are cultured in static or shear conditions are treated with constant controlled levels of shear stress in constrained flow environments. Chronic endothelial cell adaptation to shear stress can also be studied with these systems. In this review we also describe the use of a CELLMAX artificial capillary module system for shear stress experiments, utilized for long-term endothelial cell culture and chronic shear stress adaptation studies (Ballermann and Ott, 1995; Li et al., 2003; Li et al., 2004; Li et al., 2005). This system maintains a flow environment in which endothelial cells are exposed to physiologically pulsatile shear stresses, and in which one can study the cellular responses to changing levels of shear stress in the absence and presence of placental-derived hormones and growth factors.

In in vitro experimental models using cell culture methods to expose endothelial cells to shear stress, steady shear stress has been shown to upregulate eNOS mRNA levels in bovine aortic endothelial cells (BAECs) and human umbilical vein endothelial cells (HUVECs) (Ranjan et al., 1995; Uematsu et al., 1995) and ovine placental artery endothelial cells (Li et al., 2003; Li et al., 2004; Li et al., 2005). Steady laminar shear stress applied to cells grown in static culture conditions induces a biphasic production of NO in cultured HUVECs (Kuchan and Frangos, 1994). Although pulsatile laminar flow also was found to stimulate eNOS activity (Hendrickson et al., 1999; Noris et al., 1995), both eNOS mRNA and protein expression have been shown to be increased in an endothelial cell and smooth muscle cell cocultured pulsatile system (Hendrickson et al., 1999). We recently were the first to show in ovine placental artery endothelial cells that were adapted to chronic flow conditions (1-2 weeks), the dynamic time course of NO production related to the time-dependent changes in eNOS expression during various levels of pulsatile shear stress. (Li et al., 2003; Li et al., 2004; Li et al., 2005). We then determined that this NO production was both de novo and had a sterio-specific requirement for the eNOS substrate L-Arginine (Fig. 1).

Although these in vitrosystems can well mimic the shear stress caused by blood flow, understanding the true complexity of the complete picture of forces endothelial cells experience in vivo within the tunica intima is important for designing experiments and further interpreting the true significance of results. This latter somewhat ambitious goal may be achieved through sophisticated and novel mathematical and computer models for predicting shear forces in these important vascular beds. Creating these models requires a more comprehensive understanding of the coupled interaction between blood flow hemodynamics and vascular tissue mechanics as well as the vascular tissue response to hemodynamic forces (Sprague et al., 2009; Zhu et al., 2009).

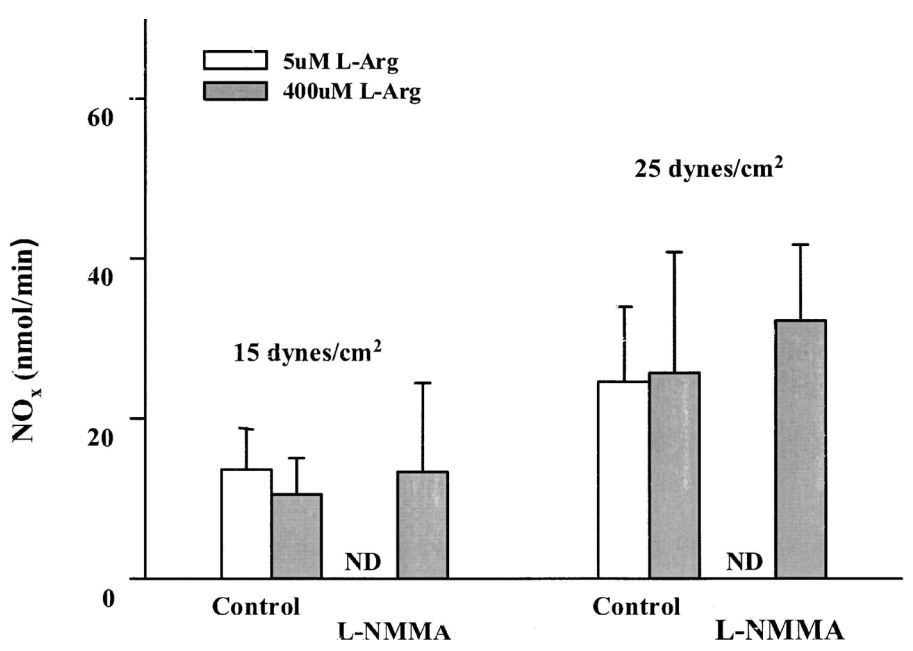

Fig. 1. Inhibition of acute NOx response of ovine fetal placental artery endothelial cells to shear stress by NG-monomethyl-L-arginine acetate (L-NMMA). Endothelial cells were grown and reached confluence at 3 dynes $/ \mathrm{cm}^{2}$. Before shear stresses were elevated to either 15 or $25 \mathrm{dynes} / \mathrm{cm}^{2}$, the endothelial cells were pretreated with 50 $\mu M$ of the NOS inhibitor L-NMMA for 30 min in the presence of either 5 $\mu \mathrm{M}$ or $400 \mu \mathrm{M}$ L-arginine. Acute NOx production (at $20 \mathrm{~min}$ ) was measured. ND, nondetectable levels. Data are means $\pm S E, n=4 /$ group. (From Li et al., 2003, with permission). 
A

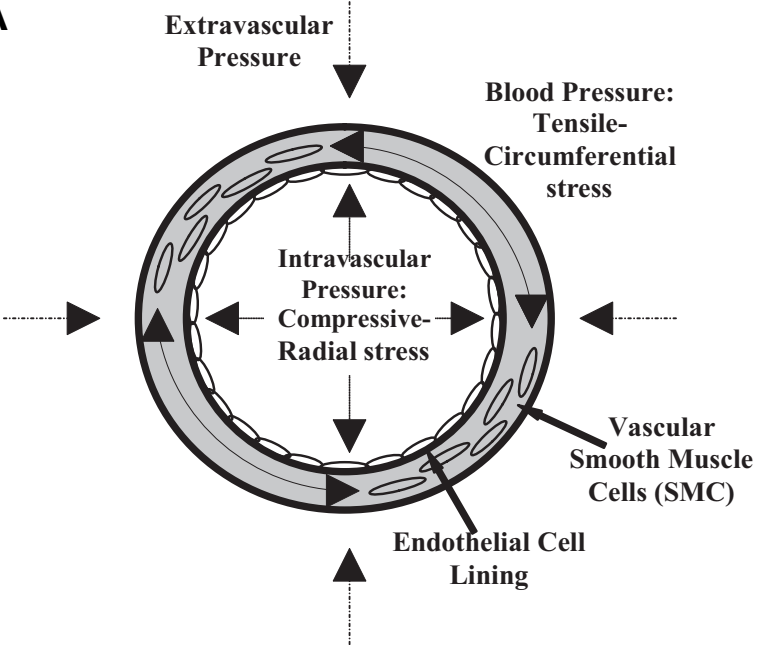

B

Tensile-

Longitudinal stress

from pressure
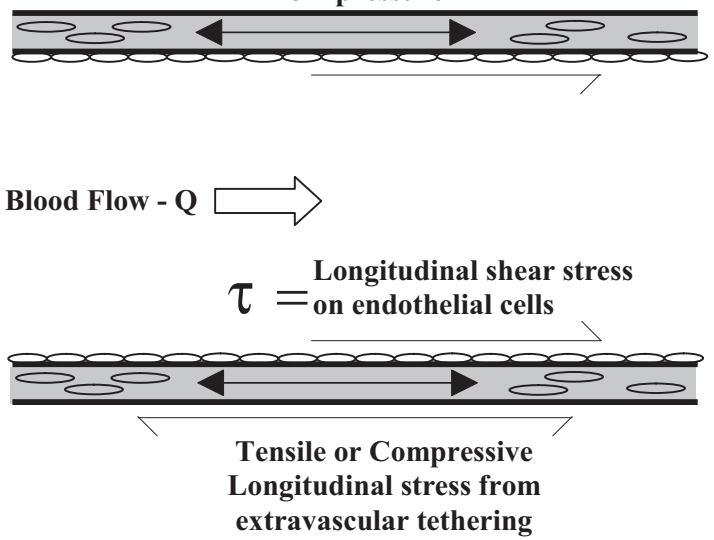

Fig. 2. Hemodynamic and extravascular stresses on blood vessels, shown in the (A) radial cross-section orientation and (B) longitudinal orientation.

\section{Hemodynamic forces acting on the vascular wall}

Blood pressure exerts compressive-radial and tensile-circumferential forces on all cell types in the vasculature wall as well as extracellular matrix proteins (Fig. 2A). Blood flow exerts longitudinal shearing forces on the cells of the blood vessel tunica intima and thus, the endothelial cells. Smooth muscle cells within the tunica media of the vessel are subjected to tensile forces in the longitudinal direction due to blood pressure and transference of shear forces on the endothelial cells (Fig. 2B). Therefore the smooth muscle cells are not physiologically exposed to shear stresses though they do not respond to shear stress in culture environment (Lee et al., 2002).

Since vessel circumference is typically larger than wall thickness, the effects of circumferential, tensile stresses (extensional forces per unit area) on cell types, especially smooth muscle cells, are the subject of more substantial research than radial, compressive stresses. The result of net pressure forces (i.e., intravascular minus extravascular pressure, or transmural pressure) is that blood vessels expand circumferentially, and in some cases we have seen longitudinally also, with the pulse pressure of a cardiac cycle. However, each of these types of forces and the strain they induce on a blood vessel can be partly counterbalanced by

A

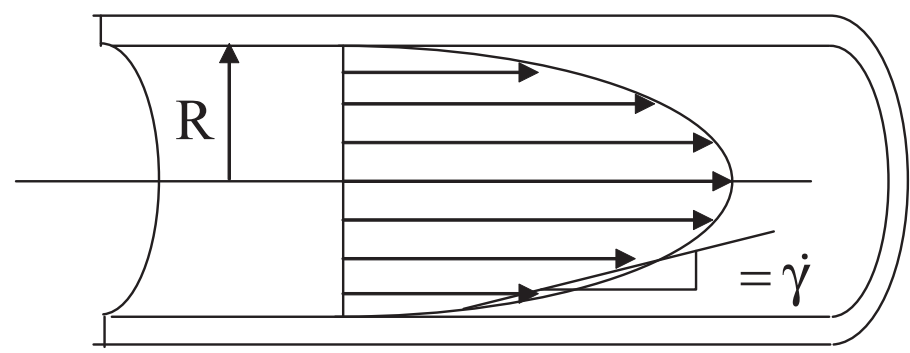

tethering of vascular tissue to surrounding structures. This tethering is best described as connective tissue surrounding and attached to the tunica adventitia of the vessel, clearly providing a support framework that reduces the amount of vessel strain.

The longitudinal shearing force caused by the flow of blood a viscous liquid - on the vessel wall results in a shear stress (force per unit area) on the cells lining the vessel lumen that is designated by $\tau$ (Fig 2B). The magnitude of this shear stress depends on the inner diameter of the vessel, blood flow rate, viscosity of the blood and pulsatility of blood flow. Under certain idealized conditions, blood flow can be considered to move in concentric layers, or lamina, such that all molecules (and cells) in one lamina are all moving at the same velocity and do not cross over into other lamina (Fig. 3). The velocity is at maximum in the central core and, in each lamina that is successively closer to the wall, the velocity is lower. Because the wall is not moving, the lamina of molecules at the wall may also be considered to not be moving. This is called the "no-slip" condition. The slope of the change in velocity from the wall to the center of the vessel is called the shear rate, signified by the symbol $\dot{\gamma}$, and in part determines the frictional forces between the wall and the moving fluid. (Bayliss, 1962). The distribution and spatial dependence of fluid velocities can be well represented by a velocity profile, diagrammed in Fig. 3 .

B

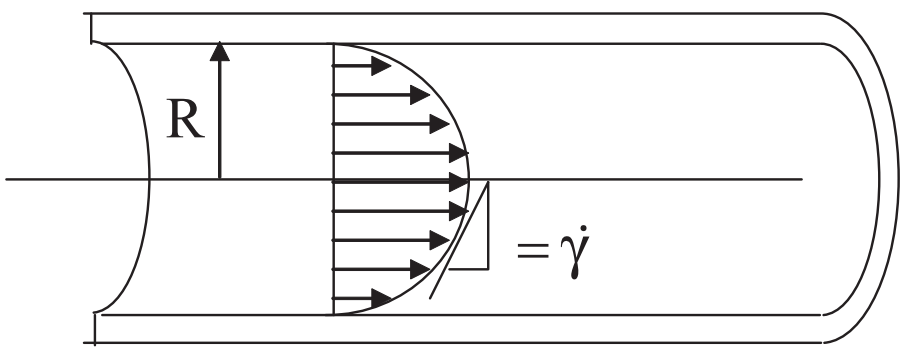

Fig. 3. Velocity profiles of parabolic flow in cases of (A) higher and (B) lower shear rates. Because shear rate is essentially the rate of fluid deformation, it has units of $1 /$ second. 
A
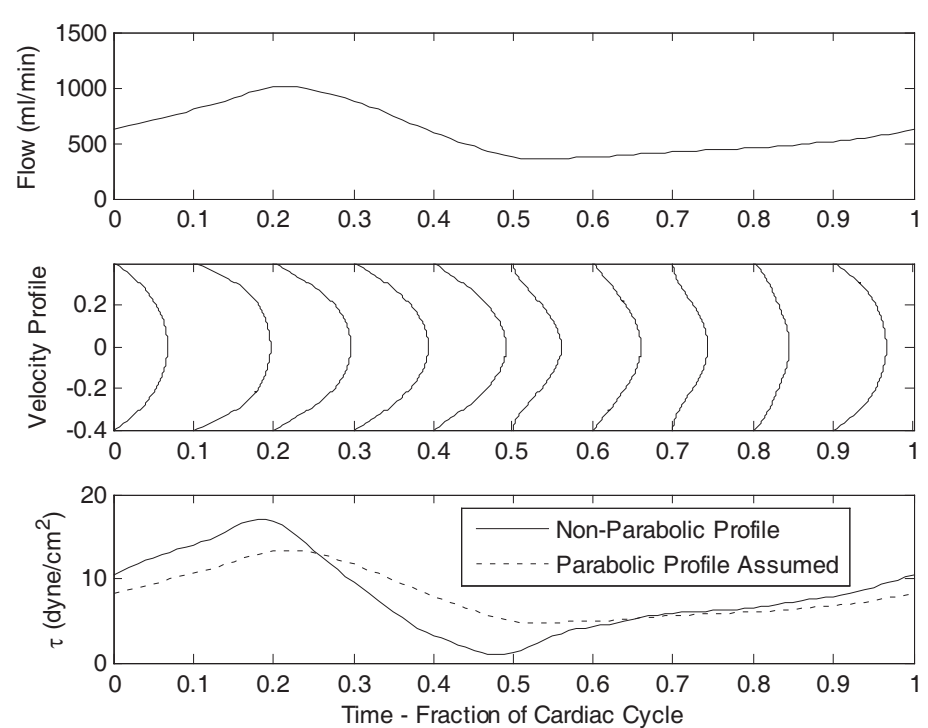

B
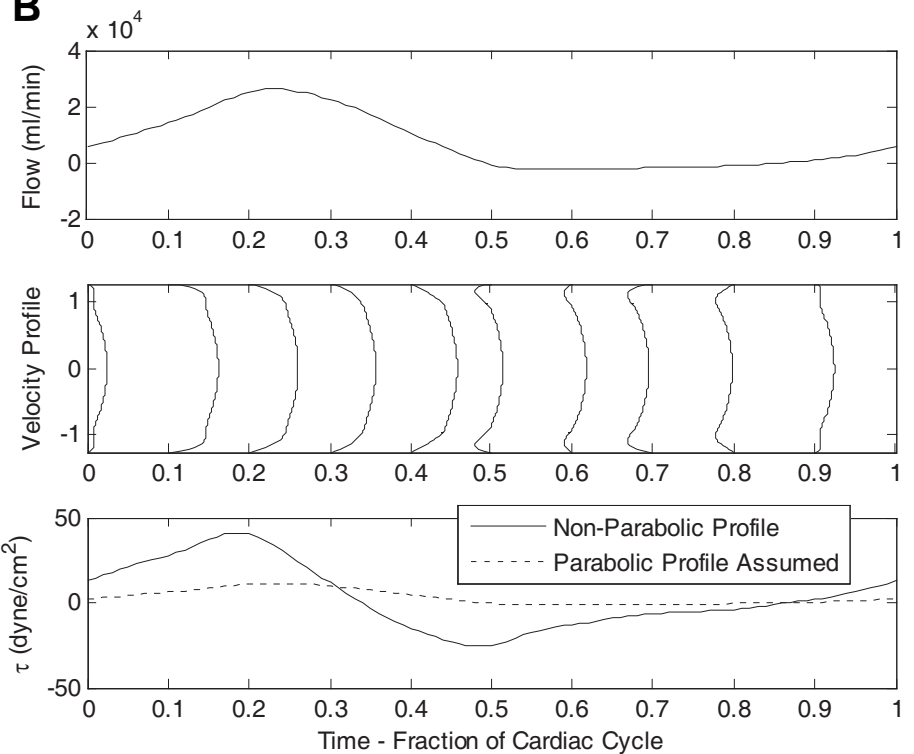

Fig. 4. Variation of flow rate, velocity, profile and shear stress throughout the cardiac cycle (Systole + Diastole) for (A) Smaller (radius = 0.4 $\mathbf{c m}$ ) and (B) Larger sized arteries, like the aorta (radius $\mathbf{= 1 . 2} \mathbf{~ c m}$ ). Within smaller arteries, the instantaneous velocity profile stays closer to a parabolic shape throughout the cardiac cycle than within the larger artery.

\section{Current calculations of in vivo shear stress}

Most in vitro and ex vivo experiment models have calculated shear stress based on measurements of mean flow rates and arterial inner diameters, and making several important assumptions. By assuming blood exhibits Newtonian fluid behavior and laminar flow, wall shear stress $(\tau)$ can be quantified by multiplying shear rate $(\dot{\gamma})$ by the fluid viscosity $(\mu)$ in which shear rate and shear stress are linearly proportional (i.e., a Newtonian fluid) using:

$$
\tau=\dot{\gamma} \cdot \mu \quad \text { (Equation 1) }
$$

Combining this with the assumption that blood vessels are long, straight, rigid tubes, and other important criteria are met such that the velocity profile in the lumen is parabolic (as seen in Fig. 2), then the fluid shear rate (Equation 2) and vessel wall shear stress (Equation 3) can be written as:

$$
\begin{array}{ll}
\dot{\gamma}=\frac{4 \cdot \mathrm{Q}}{\pi \cdot \mathrm{R}^{3}} & \text { (Equation 2) } \\
\tau=\frac{4 \cdot \mathrm{Q} \cdot \mu}{\pi \cdot \mathrm{R}^{3}} & \text { (Equation 3) }
\end{array}
$$

where $Q$ is the flow rate, $\mu$ is the viscosity of the blood and $R$ is the internal radius of the vessel. When standard calculations are made using these assumptions, it is called Poiseiulle flow analysis. This is the most commonly used estimate of in vivoshear stress.

\section{Observing the breakdown of Poiseiulle flow assump- tions - the use of computer modeling}

\section{Shear stress varies over time}

Under physiological conditions, however, especially in large distributing and elastic arteries, blood flow is pulsatile in nature.
The dynamic driving pressure from the heart causes blood flow to vary over each individual cardiac cycle. Under these pulsatile conditions, velocity profiles even in long, straight, rigid tubes with a Newtonian fluid are not consistently parabolic. Nevertheless, the equations that govern blood flow under these conditions can be solved for, such that the variability in blood flow rate, velocity profile, and wall shear stress that occur over a cardiac cycle can be computed (Fig 4). In this way, the wall shear stress that would result from an assumption of parabolic flow (dashed line) can be contrasted with the one that would result if pulsatility is taken into account (solid line). Assumptions of parabolic flow attenuate the absolute maximum of shear stress over the entire cardiac cycle. In larger vessels (Fig. 4B), this effect is especially pronounced. In smaller diameter arteries (Fig. 4A), where blood pulsation is lessened due to the pulse damping effect of healthy arteries, Poiseiulle assumptions are indeed quite reasonable.

Among the various flow types that have been studied in vitro, steady laminar flow - layered, unidirectional flow with no time dependence - has been the most investigated.

\section{Shear stress also varies due to blood behavior}

It is clear that inducing shear stress in a pulsatile fashion is an important improvement from steady shear stress to better model in vivo conditions, however many in vitro experimental models use Newtonian fluids to induce shear stress on cultured endothelial cells. However, blood is a non-Newtonian fluid, meaning the shear stress-to-shear rate of strain relationship is not linear and blood viscosity in vivois not constant throughout the vasculature. Blood is a shear-thinning fluid, behaving with a lower apparent viscosity at high shear rates. In addition, it has a yield stress, meaning that at low enough shear stresses blood flow lamina travel at the same velocity in a fashion analogous to a solid mass. Several mathematical formulations have been applied to experimental blood shear strain-shear strain rate data for better approxi- 
mations of blood viscosity, many of which are reviewed by Neofytou in 2004 (Neofytou, 2004). The Casson model is an example of a non-linear model of blood viscosity:

$$
\tau=\left(\sqrt{\tau_{y}}+\sqrt{\mu_{\infty} \cdot \dot{\gamma}}\right)^{2} \quad \text { (Equation 4) }
$$

where, $\tau_{y}$ is the yield stress of the blood, and $\mu_{\infty}$ is the asymptotic viscosity the blood approaches with very high shear rates. Perhaps not surprisingly, an increase in red blood cell concentration, measured by hematocrit levels, also increases blood viscosity. In fact both $\tau_{y}$ and $\mu_{\infty}$ directly depend on the blood hematocrit; the dependence has been approximated with the following empirical equations based on experimental data:

$$
\begin{aligned}
& \tau_{y}=80 \cdot(H c t-0.05)^{3} \quad \text { (Equation 5) } \\
& \mu_{\infty}=1.185 e^{(2.463 \cdot H c t)} \quad \text { (Equation 6) }
\end{aligned}
$$

where the hematocrit (Hct) is entered in decimal form, and the units for yield stress and asymptotic viscosity are dynes $/ \mathrm{cm}^{2}$ and $c P$, respectively. The relationships between shear stress at the luminal surface (wall shear stress) and shear rate, and apparent viscosity and shear rate for this Hct-dependent Casson model are shown in Fig. 5. For comparison, the results for a Newtonian fluid model are also shown.

The merits and drawbacks of several blood rheology models including this one are well descried in Neofytou's 2004 review of blood rheology models and will not be reiterated. However, in order to apply this model for accurately determining physiological fluid shear stress, the shear rate and hematocrit of the blood for a given size artery must be known. Flow profiles, like those illustrated in Fig. 3, along with accurate in vivo internal diameter measurements are easily obtained for larger arteries using noninvasive ultrasound, and from these shear rate and apparent blood viscosity can be approximated within an individual experimental subject. However, these measurements become increasing difficult for smaller arteries, especially resistance-sized arteries that would be expected to have the greatest difference in shear rate and the greatest difficulty in measuring both velocity and internal diameter.

In addition, this model of blood viscosity may only be applicable for blood flow in vessels larger than $1 \mathrm{~mm}$. Below this threshold, which is much larger than a capillary, the arrangement and orientation of individual red blood cells begin to play an influential role in the blood behavior as reviewed by Christini and Kassab (2005). Specifically, blood viscosity and hematocrit significantly decrease in vessels smaller than $1 \mathrm{~mm}$ diameter due to the Fahraeus-Lindqvist effect. In addition, in even smaller vessels, the mechanical interactions that occur between single red blood cells and the endothelial cell lining significantly impact the forces that blood flow exerts on endothelial cells. For this reason, the understanding gathered about endothelial cell response to shear stress from in vitroexperimental models currently being done may mainly be applied to arteries larger than $1 \mathrm{~mm}$. Different in vitro experimental models may need to be developed to mimic shear stress in smaller arteries to learn more about the response of resistance vessels to shear stress and the effects of individual red blood cells on endothelial cell surfaces.

Indeed, as suggested by Fig. 5 , it is within the capillaries that the Newtonian model of blood is least applicable. The slowed blood flow velocity (and therefore lower shear rate) necessary to allow for nutrient and oxygen exchange causes a significant increase in blood viscosity which is offset by the fall in hematocrit.
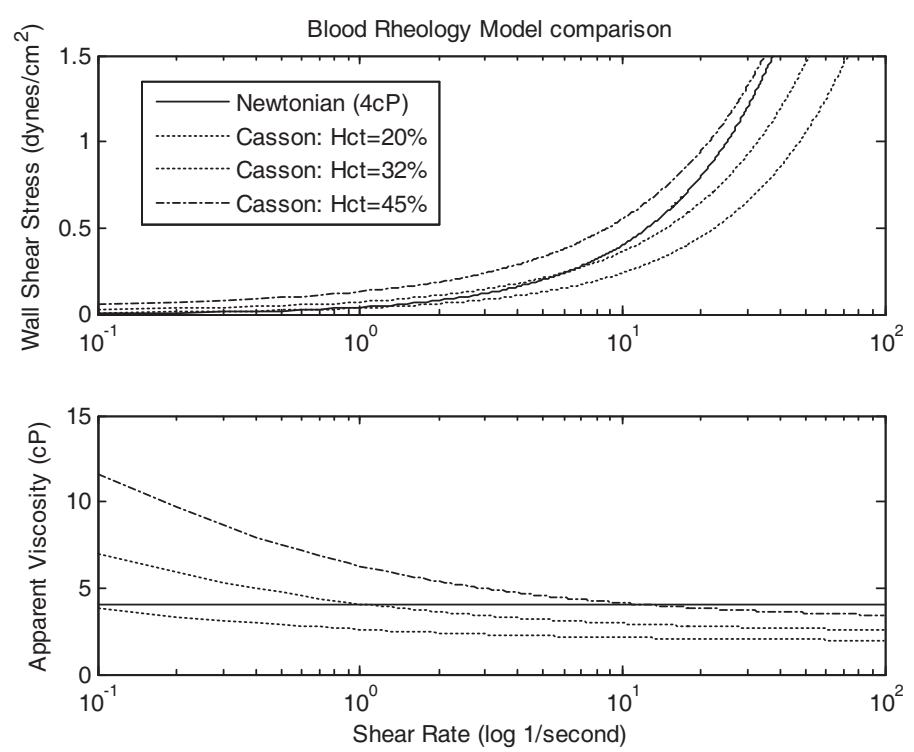

Fig. 5. Comparison of the Newtonian fluid model of a single constant viscosity (solid) and Casson fluid models of blood hematocrit of $\mathbf{2 0 \%}, \mathbf{3 2} \%$ and $\mathbf{4 5 \%}$. At normal hematocrit levels of $32-43 \%$, blood viscosity significantly varies from the Newtonian-assumed constant viscosity at shear rates less than $1 /$ second.

Using a shear-thinning fluid within the in vitro experimental models to impose shear stress on endothelial cells would be a better model of in vivoconditions, but will add additional variables not addressed by this review (e.g. cell-cell interaction and adhesion markers).

\section{Shear stress varies by location in body}

As our equation for wall shear stress suggests (Equation 3), the shear stress in a given vessel will vary with the change of vessel diameter and blood flow rate that occurs at each bifurcation in an arterial tree. Several studies including our own (Joyce et al., 2002a; Joyce et al., 2002b) have combined matched experimental data to governing equations that can be used to model and deduce shear stress distribution within these tree networks. However, the fluid flow assumptions of these studies have varied, as have their conclusions regarding shear stress distribution in the body. Although the increase in NO production with greater amounts of flow and shear stress is well known, to our knowledge, no studies have accurately predicted the distribution of shear stress within the vascular tree of the uterine or fetal placental arteries.

Conflicting predictions of the variance of wall shear stress within the systemic vascular system have been made based on a variety of modeling and data collection techniques. Historically, this dates back to Murray's Law, originally developed in 1926, which hypothesizes that shear stress is normalized throughout a vascular branching network in order to optimize the metabolic cost of pumping blood within the body against the cost of maintaining that blood volume. This theory, along with blood volume conservation, predicts a bifurcation of vascular networks in which the parent vessel radius raised to the third power is equal to the sum of the daughter vessels radii also cubed, as shown in Equation 7 and Fig. 6, 


$$
a_{0}^{3}=a_{1}^{3}+a_{2}^{3} \quad \text { (Equation 7) }
$$

where $a_{0}$ is the radius of the parent vessel and $a_{1}$ and $a_{2}$ are the radii of the subsequent daughter vessels in the bifurcation (and $\mathrm{a}_{1}$ is defined to be the larger of the two). More complex extensions of this theory incorporate the angle at which the daughter vessels branch from the parent vessel and, the changing of the viscosity of the blood (due to the shear thinning effect described above) to more accurately describe the metabolic cost of pumping blood (Neofytou, 2004).

Experimental and modeling studies comparing steady and pulsatile wall shear stress values between anatomical locations in a vascular network of an animal or human have shown shear stress to vary quite dramatically (Cheng et al., 2007; Dammers et al., 2002; Stroev et al., 2007). But modeling of shear stress distribution within a single vascular network based on pulsatile flow wave forms (Painter et al., 2006) predicts a consistent amount of shear stress in medium and smaller size vessels, only deviating from the Murray's Law prediction when comparing large arteries, such as the aorta, to smaller arteries, responsible for the resistance of vascular bed. Imaging of the rat renal vascular network has only somewhat shown adherence to Murray's Law, (Nordsletten et al., 2006); but structural measurements of the pig coronary tree found the power law relationship between parent and daughter radii to have an exponent closer to two, instead of three predicted by Murray's Law. These data indicate an increase in average wall shear stress from larger to smaller arteries with each arterial bifurcation (Mittal et al., 2005), consistent with our predictions of in vivo shear stress in the ovine uterine vascular network relative to that within the mesometrium (Joyce et al., 2002 $a, b)$.

This difference in conclusions can possibly be explained by recent further theory development and modeling of Murray's Law by Kassab's group (Kassab, 2006; Liu and Kassab, 2007). The maintenance of the vascular tissue of a branching network requires a certain metabolic expenditure. The cost of this maintenance varies with the morphology of the smaller arteries of the network, for example dependent on the ratio of artery wall thickness to outer diameter. Because this morphology, and therefore the metabolic cost and energy dissipation, can vary between different branching structures, the energy expenditure of the pumping heart can still be optimized while the amount of artery wall shear stress increases with each bifurcation. To our knowledge, no studies have gathered the necessary and complex information needed to perform an accurate analysis of this type on the placental or uterine vascular networks. One of our goals is to accurately and definitively collect matched viscosities, artery

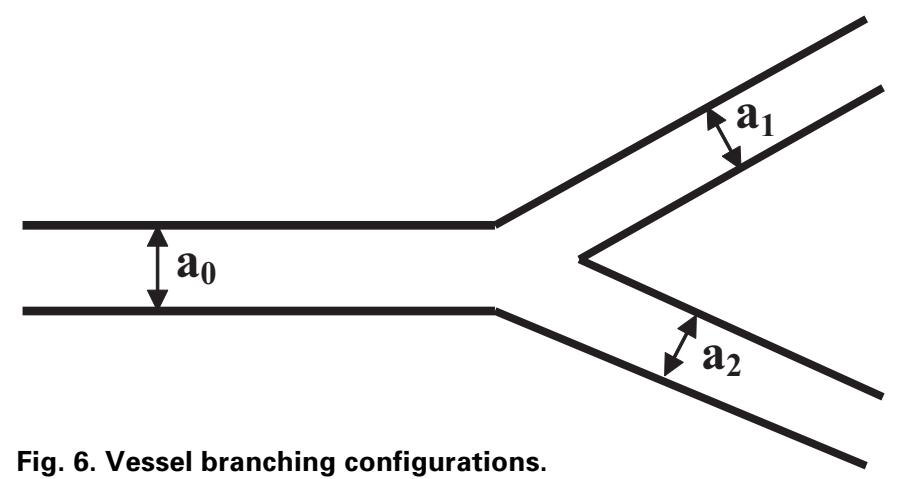

diameter, blood flow, and pressure measurements throughout the uterine vascular tree in order to calculate the shear stress distribution. By observing this distribution in healthy pregnancies and those with cardiovascular complications (e.g. preeclampsia and IUGR), we can better identify abnormalities in uterine hemodynamics and possibly verify and localize the deficiency in the NOmediated dilation response to shear stress.

\section{Conclusion}

The use of mathematical modeling to understand mechanical, chemical and physiological phenomenon in the body has allowed us to anticipate the complexities of the cardiovascular system with more precision than any measurement tool could give us. In vitro experimental models of cultured endothelial cells have shown us that shear stress plays a critical role in regulating the production of $\mathrm{NO}$, and expression of eNOS and thus eventually vascular smooth muscle cell tone. This thereby allows sufficient blood flow and nourishment to the fetus during gestation. But to learn more from these in vitro models, mathematical modeling of hemodynamics and rheology can be used to improve their congruency with in vivo conditions. Understanding the pulsatile nature of blood flow and the resulting transient nature of shear stress imposed on endothelial cells is the first step in this process.

In particular, blood viscosity directly affects the level and nature of shear stress exerted on endothelial cells. From past experimental data and computer modeling to match, we can quantify the non-linear relationship between shear rate and viscosity, and extrapolate to the effects of blood flow on endothelial cells including imaging techniques that capture vessel diameter. To mimic these forces on endothelial cells cultured in vitro, we propose the use of non-Newtonian fluids in addition to pulsatile flow to more accurately induce in vivo shear stresses on cultured endothelial cells.

Estimating the distribution of shear stress in uterine and placental arterial networks would allow in vitromodels of cultured endothelial cells to accurately match in vivo conditions and provide a better understanding of the role of $\mathrm{NO}$ in the regulation of vascular tone and adaptation. If, as we anticipate, the level of wall shear stress is found to vary between locations in an arterial tree and change with pregnancy, inferences could be made about the level of shear stress transduction and NO production/eNOS expression by endothelial cells at these locations. With this knowledge in hand, locations of defective mechanisms of vessel dilation could possibly be determined in states of insufficient blood flow to the fetus during gestation.

\section{Acknowledgement}

The authors thank Terrance Phernetton, Gladys Lopez, Jason Austin, and Kreg Grindle for the technicalsupport in preparing the endothelial cell preparations, and also Cindy Goss for help in the preparation of this manuscript. This work is supported, in part, by NIH grants HD38843, HL49210, HL08714, and HL086939.

\section{References}

BALLERMANN, B. J., and OTT, M. J. (1995). Adhesion and differentiation of endothelial cells by exposure to chronic shear stress: a vascular graft model. Blood Purif 13: 125-134.

BAYLIS, C., and ENGELS, K. (1992). Adverse interactions between pregnancy and 
a new model of systemic hypertension produced by chronic blockade of endothelium derived relaxing factor (EDRF) in the rat. Clin Exp Hyper PregB11: 117-129.

BAYLISS, L. E. (1962). Handbook for Physiology, Section 2: Circulation, Vol. 1 Chapter 8. Reology of blood: 137.

BUSSE, R., and MULSCH, A. (1990). Calcium-dependent nitric oxide synthesis in endothelial cytosol is mediated by calmodulin. FEBS Lett 265: 133-136.

CHANG, J. K., ROMAN, C., and HEYMANN, M. A. (1992). Effect of endotheliumderived relaxing factor inhibition on the umbilical-placental circulation in fetal lambs in utero. Am J Obstet Gyneco/ 166: 727-734.

CHENG, C., HELDERMAN, F., TEMPEL, D., SEGERS, D., HIERCK, B., POELMANN, R., VAN TOL, A., DUNCKER, D. J., ROBBERS-VISSER, D., URSEM, N. T., VAN HAPEREN, R., WENTZEL, J. J., GIJSEN, F., VAN DER STEEN, A. F., DE CROM, R., and KRAMS, R. (2007). Large variations in absolute wall shear stress levels within one species and between species. Atherosclerosis 195: 225-235.

COCKELL, A. P., and POSTON, L. (1997). Flow-mediated vasodilatation is enhanced in normal pregnancy but reduced in preeclampsia. Hypertension 30 : 247-251.

CONRAD, K. P., and WHITTEMORE, S. L. (1992). NG-monomethyl-L-arginine and nitroarginine potentiate pressor responsiveness of vasoconstrictors in conscious rats. Am J Physio/262: R1137-1144.

CRISTINI, V., and KASSAB, G. S. (2005). Computer modeling of red blood cell rheology in the microcirculation: a brief overview. Ann Biomed Eng 33: 17241727.

DAMMERS, R., TORDOIR, J. H., HAMELEERS, J. M., KITSLAAR, P. J., and HOEKS, A. P. (2002). Brachial artery shear stress is independent of gender or age and does not modify vessel wall mechanical properties. Ultrasound Med Bio/28: 1015-1022.

DAVIES, P. F., REMUZZI, A., GORDON, E. J., DEWEY, C. F., JR., and GIMBRONE, M. A., JR. (1986). Turbulent fluid shear stress induces vascular endothelial cell turnover in vitro. Proc Nat/ Acad Sci USA 83: 2114-2117.

FOX, S. B., and KHONG, T. Y. (1990). Lack of innervation of human umbilical cord. An immunohistological and histochemical study. Placenta 11: 59-62.

FUKAYA, Y., and OHHASHI, T. (1996). Acetylcholine- and flow-induced production and release of nitric oxide in arterial and venous endothelial cells. Am J Physiol 270: H99-106.

GIMBRONE, M. A., Jr., TOPPER, J. N., NAGEL, T., ANDERSON, K. R., and GARCIA-CARDENA, G. (2000). Endothelial dysfunction, hemodynamic forces, and atherogenesis. Ann N Y Acad Sci902: 230-239; discussion 239-240.

HARRISON, D. G., SAYEGH, H., OHARA, Y., INOUE, N., and VENEMA, R. C. (1996). Regulation of expression of the endothelial cell nitric oxide synthase. Clin Exp Pharmacol Physio/23: 251-255.

HENDRICKSON, R. J., CAPPADONA, C., YANKAH, E. N., SITZMANN, J. V., CAHILL, P. A., and REDMOND, E. M. (1999). Sustained pulsatile flow regulates endothelial nitric oxide synthase and cyclooxygenase expression in co-cultured vascular endothelial and smooth muscle cells. J Mo/ Cel/ Cardio/31: 619-629.

ITOH, H., BIRD, I. M., NAKAO, K., and MAGNESS, R. R. (1998). Pregnancy increases soluble and particulate guanylate cyclases and decreases the clearance receptor of natriuretic peptides in ovine uterine, but not systemic, arteries. Endocrinology 139: 3329-3341.

JOYCE, J. M., PHERNETTON, T. M., and MAGNESS, R. R. (2002a). Effect of uterine blood flow occlusion on shear stress-mediated nitric oxide production and endothelial nitric oxide synthase expression during ovine pregnancy. Biol Reprod 67: 320-326.

JOYCE, J. M., PHERNETTON, T. M., SHAW, C. E., MODRICK, M. L., and MAGNESS, R. R. (2002b). Endothelial vasodilator production by uterine and systemic arteries. IX. eNOS gradients in cycling and pregnant ewes. $\mathrm{Am} \mathrm{J}$ Physiol Heart Circ Physiol282: H342-348.

KASSAB, G. S. (2006). Scaling laws of vascular trees: of form and function. $A m J$ Physiol Heart Circ Physio/290: H894-903.

KUBLICKIENE, K. R., LINDBLOM, B., KRUGER, K., and NISELL, H. (2000). Preeclampsia: evidence for impaired shear stress-mediated nitric oxide release in uterine circulation. Am J Obstet Gyneco/183: 160-166.

KUCHAN, M. J., and FRANGOS, J. A. (1994). Role of calcium and calmodulin in flow-induced nitric oxide production in endothelial cells. Am J Physio/ 266
C628-636.

KWON, H., WU, G., MEININGER, C. J., BAZER, F. W., and SPENCER, T. E. (2004). Developmental changes in nitric oxide synthesis in the ovine placenta. Biol Reprod 70: 679-686.

LEE, A. A., GRAHAM, D. A., DELA CRUZ, S., RATCLIFFE, A., and KARLON, W. J. (2002). Fluid shear stress-induced alignment of cultured vascular smooth muscle cells. J Biomech Eng 124: 37-43.

LEVESQUE, M. J., and NEREM, R. M. (1985). The elongation and orientation of cultured endothelial cells in response to shear stress. J Biomech Eng 107: 341 . 347.

LI, Y., ZHENG, J., BIRD, I. M., and MAGNESS, R. R. (2003). Effects of pulsatile shear stress on nitric oxide production and endothelial cell nitric oxide synthase expression by ovine fetoplacental artery endothelial cells. Bio/Reprod69: 10539.

LI, Y., ZHENG, J., BIRD, I. M., and MAGNESS, R. R. (2004). Mechanisms of shear stress-induced endothelial nitric-oxide synthase phosphorylation and expression in ovine fetoplacental artery endothelial cells. Biol Reprod70: 785-796.

LI, Y., ZHENG, J., BIRD, I. M., and MAGNESS, R. R. (2005). Effects of pulsatile shear stress on signaling mechanisms controlling nitric oxide production, endothelial nitric oxide synthase phosphorylation, and expression in ovine fetoplacental artery endothelial cells. Endothelium 12: 21-39.

LIE, M., SEJERSTED, O. M., and KIIL, F. (1970). Local regulation of vascular cross section during changes in femoral arterial blood flow in dogs. Circ Res 27: $727-$ 737.

LIU, Y., and KASSAB, G. S. (2007). Vascular metabolic dissipation in Murray's law. Am J Physiol Heart Circ Physio/292: H1336-1339.

MAGNESS, R. R. (1998). Maternal cardiovascular and other physiologic responses to the endocrinology of pregnancy. In The Endocrinology of Pregnancy. (Ed. F.W. Bazer). Humana Press Inc. Totowa, NJ, USA. Chapter 2, pp. 507-539.

MAGNESS, R. R., PHERNETTON, T. M., and ZHENG, J. (1998). Systemic and uterine blood flow distribution during prolonged infusion of 17beta-estradiol. $\mathrm{Am}$ $J$ Physio/275: H731-743.

MAGNESS, R. R., ROSENFELD, C. R., HASSAN, A., and SHAUL, P. W. (1996) Endothelial vasodilator production by uterine and systemic arteries. I. Effects of ANG II on PGI2 and NO in pregnancy. Am J Physio/270: H1914-1923.

MAGNESS, R. R., SHAW, C. E., PHERNETTON, T. M., ZHENG, J., and BIRD, I. M. (1997). Endothelial vasodilator production by uterine and systemic arteries. II. Pregnancy effects on NO synthase expression. Am J Physio/272: H17301740.

MAGNESS, R. R., SULLIVAN, J. A., LI, Y., PHERNETTON, T. M., and BIRD, I. M (2001). Endothelial vasodilator production by uterine and systemic arteries. VI. Ovarian and pregnancy effects on eNOS and $\mathrm{NO}(\mathrm{x})$. Am J Physiol Heart Circ Physio/280: H1692-1698.

MAGNESS, R. R., and ZHENG, J. (1996). Maternal cardiovascular alterations during pregnancy. Arnold Publishing, London.

MAYER, B., and HEMMENS, B. (1997). Biosynthesis and action of nitric oxide in mammalian cells. Trends Biochem Sci22: 477-481.

MCCORMICK, S. M., ESKIN, S. G., MCINTIRE, L. V., TENG, C. L., LU, C. M., RUSSELL, C. G., and CHITTUR, K. K. (2001). DNA microarray reveals changes in gene expression of shear stressed human umbilical vein endothelial cells. Proc Natl Acad Sci USA 98: 8955-8960.

MITTAL, N., ZHOU, Y., LINARES, C., UNG, S., KAIMOVITZ, B., MOLLOI, S., and KASSAB, G. S. (2005). Analysis of blood flow in the entire coronary arterial tree. Am J Physiol Heart Circ Physio/289: H439-446.

MOLNAR, M., and HERTELENDY, F. (1992). N omega-nitro-L-arginine, an inhibitor of nitric oxide synthesis, increases blood pressure in rats and reverses the pregnancy-induced refractoriness to vasopressor agents. Am J Obstet Gynecol 166: $1560-1567$.

MYATT, L. (1992). Control of vascular resistance in the human placenta. Placenta 13: 329-41.

NADAUD, S., PHILIPPE, M., ARNAL, J. F., MICHEL, J. B., and SOUBRIER, F. (1996). Sustained increase in aortic endothelial nitric oxide synthase expression in vivo in a model of chronic high blood flow. Circ Res 79: 857-863.

NEOFYTOU, P. (2004). Comparison of blood rheological models for physiological flow simulation. Biorheology 41: 693-714. 
NORDSLETTEN, D. A., BLACKETT, S., BENTLEY, M. D., RITMAN, E. L., and SMITH, N. P. (2006). Structural morphology of renal vasculature. Am J Physiol Heart Circ Physio/291: H296-309.

NORIS, M., MORIGI, M., DONADELLI, R., AIELLO, S., FOPPOLO, M., TODESCHINI, M., ORISIO, S., REMUZZI, G., and REMUZZI, A. (1995). Nitric oxide synthesis by cultured endothelial cells is modulated by flow conditions. Circ Res 76: 536543.

PAINTER, P. R., EDEN, P., and BENGTSSON, H. U. (2006). Pulsatile blood flow, shear force, energy dissipation and Murray's Law. Theor Biol Med Model: 31.

RANJAN, V., XIAO, Z., and DIAMOND, S. L. (1995). Constitutive NOS expression in cultured endothelial cells is elevated by fluid shear stress. Am J Physio/269: H550-555.

REYNOLDS, L. P., and REDMER, D. A. (1995). Utero-placental vascular development and placental function. J Anim Sci73: 1839-1851.

ROSENFELD, C. R., COX, B. E., ROY, T., and MAGNESS, R. R. (1996). Nitric oxide contributes to estrogen-induced vasodilation of the ovine uterine circulation. $J$ Clin Invest 98: 2158-2166.

ROWE, J., CAMPBELL, S., and GALLERY, E. D. (2003). Nitric oxide production by decidual endothelial cells is not reduced in preeclampsia. Hypertens Pregnancy 22: 63-75.

SHEPPARD, C., SHAW, C. E., LI, Y., BIRD, I. M., and MAGNESS, R. R. (2001). Endothelium-derived nitric oxide synthase protein expression in ovine placental arteries. Biol Reprod 64: 1494-1499.

SLADEK, S. M., MAGNESS, R. R., and CONRAD, K. P. (1997). Nitric oxide and pregnancy. Am J Physio/272: R441-463.

SPRAGUE,B.J., PHERNETTON, T.M., MAGNESS, R.R. and CHESLER, N.C. (2009). The effects of the ovarian cycle and pregnancy on uterine vascular impedance and uterine artery mechanics. Eur J Obstet Gynecol Reprod Biol. 144 Suppl 1: S170-178.

STROEV, P. V., HOSKINS, P. R., and EASSON, W. J. (2007). Distribution of wall shear rate throughout the arterial tree: a case study. Atherosclerosis 191: 276280.
UEMATSU, M., OHARA, Y., NAVAS, J. P., NISHIDA, K., MURPHY, T. J., ALEXANDER, R. W., NEREM, R. M., and HARRISON, D. G. (1995). Regulation of endothelial cell nitric oxide synthase mRNA expression by shear stress. $\mathrm{Am}$ J Physio/269: C1371-1378.

VAN BUREN, G. A., YANG, D. S., and CLARK, K. E. (1992). Estrogen-induced uterine vasodilatation is antagonized by $L$-nitroarginine methyl ester, an inhibitor of nitric oxide synthesis. Am J Obstet Gyneco/167: 828-833.

VEQUAUD, P., and FRESLON, J. L. (1996). Components of flow-induced dilation in rat perfused coronary artery. Cel/ Biol Toxico/12: 227-32.

XIAO, Z., ZHANG, Z., RANJAN, V., and DIAMOND, S. L. (1997). Shear stress induction of the endothelial nitric oxide synthase gene is calcium-dependent but not calcium-activated. J Cell Physio/171: 205-211.

YALLAMPALLI, C., and GARFIELD, R. E. (1993). Inhibition of nitric oxide synthesis in rats during pregnancy produces signs similar to those of preeclampsia. $\mathrm{Am}$ J Obstet Gynecol169: 1316-1320.

YANG, D., LANG, U., GREENBERG, S. G., MYATT, L., and CLARK, K. E. (1996). Elevation of nitrate levels in pregnant ewes and their fetuses. Am J Obstet Gyneco/174: 573-577.

YI, F. X., MAGNESS, R. R., and BIRD, I. M. (2005). Simultaneous imaging of [Ca2+] and intracellular NO production in freshly isolated uterine artery endothelial cells: effects of ovarian cycle and pregnancy. Am J Physiol Regul Integr Comp Physio/288: R140-8.

ZHENG, J., LI, Y., WEISS, A. R., BIRD, I. M., and MAGNESS, R. R. (2000). Expression of endothelial and inducible nitric oxide synthases and nitric oxide production in ovine placental and uterine tissues during late pregnancy. Placenta 21: 516-24.

ZHU, Y., SPRAGUE, B.J., PHERNETTON, T.M., MAGNEGSS, R.R., and CHESLER, N.C. (2009). Transmission line models to simulate the impedance of the uterine vasculature during the ovarian cycle and pregnancy. Eur J Obstet Guynecol Reprod Biol. 144 Suppl 1: S-184-191. 


\section{Further Related Reading, published previously in the Int. J. Dev. Biol.}

See our recent Special Issue Epigenetics \& Development edited by Saadi Khochbin and Stefan Nonchev at: http://www.ijdb.ehu.es/web/contents.php?vol=53\&issue=2-3

See Special Issue Pattern Formation edited by Michael K. Richardson and Cheng-Ming Chuong at: http://www.ijdb.ehu.es/web/contents.php?vol=53\&issue=5-6

The influence of the intrauterine environment on human placental development Graham J. Burton, Eric Jauniaux and D. Stephen Charnock-Jones Int. J. Dev. Biol. (2010) 54: 303-312 (doi: 10.1387/ijdb.082764gb)

Estrogen regulation of placental angiogenesis and fetal ovarian development during primate pregnancy

Eugene D. Albrecht and Gerald J. Pepe

Int. J. Dev. Biol. (2010) 54: 397-408 (doi: 10.1387/ijdb.082758ea)

In preeclampsia, the placenta grows slowly along its minor axis

Eero Kajantie, Kent Thornburg, Johan G.Eriksson, Clive Osmond and David J.P. Barker Int. J. Dev. Biol. (2010) 54: 469-473 (doi: 10.1387/ijdb.082833ek)

Developmental cell biology of human villous trophoblast: current research problems John D. Aplin

Int. J. Dev. Biol. (2010) 54: 323-329 (doi: 10.1387/ijdb.082759ja)

The human placenta becomes haemochorial at the 13th week of pregnancy.

J M Foidart, J Hustin, M Dubois and J P Schaaps

Int. J. Dev. Biol. (1992) 36: 451-453

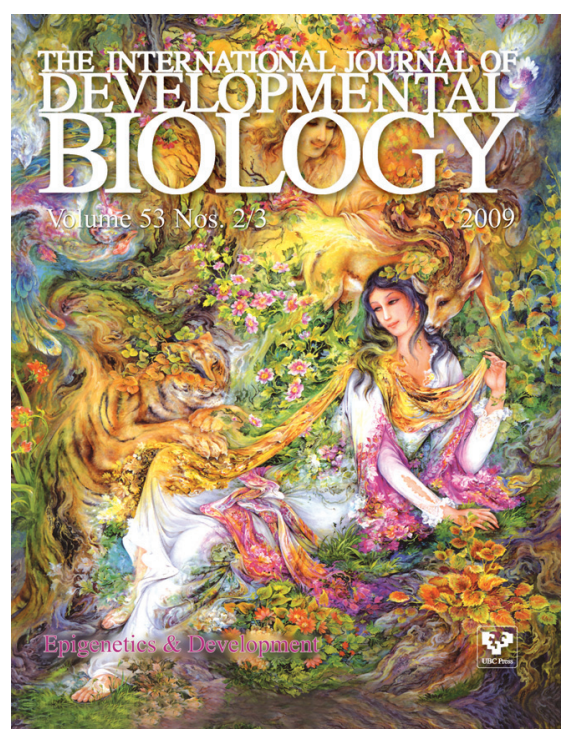

5 yr ISI Impact Factor $(2008)=3.271$

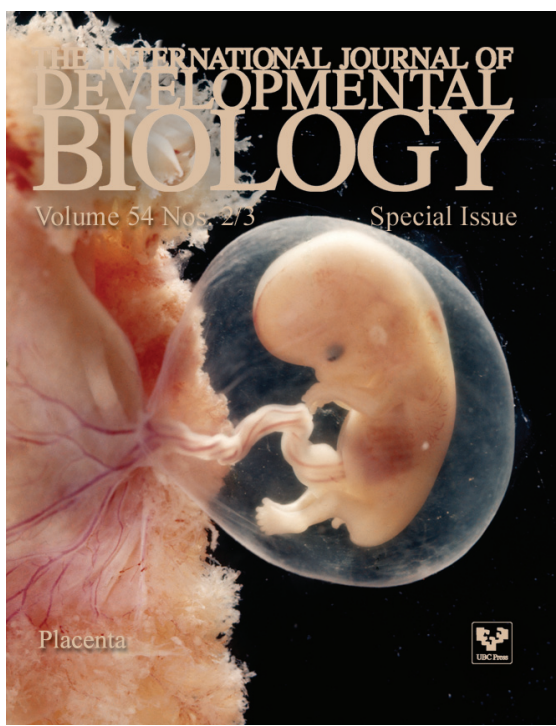

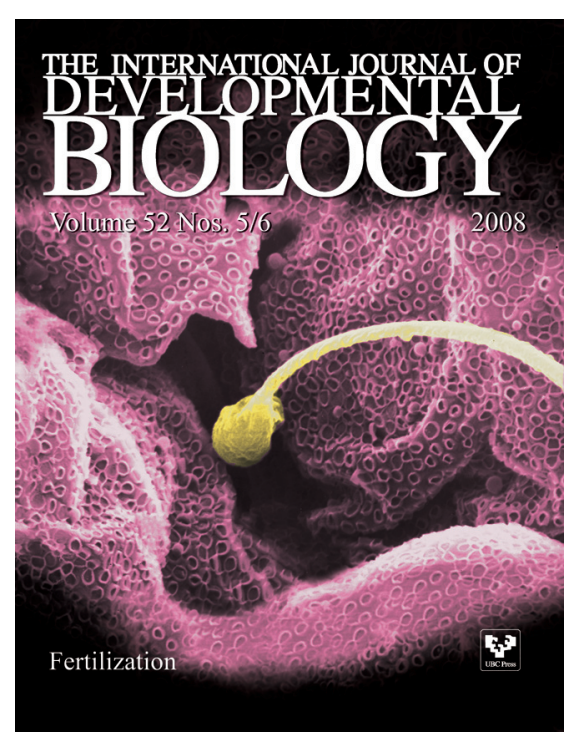

